\title{
ANTÍGENO DA HEPATITE B NA SINDROME DE DOWN
}

\author{
ROBERTo DE Almeida Moura * \\ BeNJAMIN JosÉ SchmidT** \\ ARON J. Diament *** \\ STANISLAU KRYNSKI ****
}

A descoberta do antígeno australiano (hoje conhecido como antígeno da hepatite B ou simplesmente HBAg), começou, em 1961, com uma investigação sistemática do soro de pacientes que tinham recebido grande número de transfusões, na esperança de encontrar anticorpos contra algum componente estranho eventualmente presente no sangue dos doadores. Usando a técnica de dupla difusão em ágar (técnica de Ouchterlony), Blumberg e col. ${ }^{3}, 4$, procuraram anticorpos precipitantes que poderiam ter se desenvolvido nesses pacientes contra determinantes antigênicos presentes no soro dos doadores e que fossem estranhos aos receptores ou então antígenos que precipitassem anticorpos induzidos nos receptores provenientes de materiais exógenos (p.ex.: microrganismos) eventualmente presentes no sangue dos doadores. Esses autores descreveram um sistema complexo de especificidades antigênicas hereditárias, de baixa densidade (beta-lipoproteínas), o sistema Ag, análogo ao dos grupos sangüíneos ${ }^{6}$. Logo após à descoberta do anticorpo antilipoproteína, Blumberg ${ }^{1}$ demonstrou a presença de anticorpos precipitantes que reagiam contra um antígeno diferente das lipoproteínas, encontrável no soro de alguns pacientes. Esses anticorpos apareciam freqüentemente em pacientes com hemofilia e em outros que tinham recebido grande número de transfusões ${ }^{5}$. Como o antígeno foi identificado pela primeira vez num aborígene australiano foi chamado de antígeno australiano ou antígeno Austrália, ou ainda, antígeno $\mathrm{Au}$. $\mathrm{O}$ anti-soro correspondente foi denominado de anti-Au.

Logo após esta descoberta tornou-se evidente que o antígeno estava estreitamente relacionado a um virus de hepatite ou poderia estar diretamente localizado em tal vírus. As evidências para esse tipo de interpretação vieram de vários tipos de observações, estando entre elas as seguintes: a) o antígeno HBAg é raro em pessoas normais mas é freqüentemente en-

* Professor Titular da Microbiologia e Imunologia da Faculdade de Medicina do $\mathrm{ABC}$ e Professor Livre-Docente e Responsável pela Disciplina de Microbiologia e Imunologia Clínica da Faculdade de Ciências Farmacêuticas da Universidade de São Paulo; ** Professor Titular de Pediatria da Faculdade de Medicina de Sorocaba e Livre-Docente de Pediatria da Escola Paulista de Medicina; *** Professor Assistente do Departamento de Neuropsiquiatria (Divisão de Neurologia) do Hospital das Clínicas da Faculdade de Medicina da Universidade de São Paaulo; **** Psiquiatra, Diretor Técnico do Centro de Habilitação da APAE de São Paulo. 
contrado em pacientes com hepatite viral ${ }^{8,9}$ e não está associado a outras doenças hepáticas ${ }^{3}, 12,14$; b) alguns pacientes que tinham recebido sangue de doadores com antígeno HBAg tiveram hepatite e passaram a apresentar o antígeno no soro ${ }^{2}, 8$, o que indica que o antígeno comporta-se como agente infeccioso; c) o antígeno $\mathrm{HBAg}$ ocorre em cerca de $30 \%$ dos pacientes com sindrome de Down (mongolóides) hospitalizados ${ }^{2}$, nos quais há uma hepatite crônica anictérica demonstrada por biopsia e por meio de taxas elevadas de transaminase glutâmica-pirúvica (TGP).

Devido a essa percentagem de presença de HBAg tem havido especulações de ordem etiológica para a sindrome de Down que seria indiretamente induzida por essa infecção viral. No sentido de verificar a presença de antígeno HBAg, propusemo-nos a analisar os soros de um grupo de crianças com sindrome de Down, juntamente com os soros de seus familiares.

\section{MATERIAL E MÉTODOS}

Para o estudo de crianças apresentando a sindrome de Down, utilizamos o soro de 30 crianças matriculadas no Centro de Habilitação da Associação de Pais e Amigos dos Excepcionais de São Paulo (APAE) e conseguimos também amostras de soro de irmãos normais de 28 dessas crianças, bem como de 19 mães, num total de 77 soros. Os sangues foram colhidos, separados com assepsia e congelados até a realização das provas.

A determinação da presença de HBAg foi feita pela técnica da contra-imunoeletroforese utilizando o equipamento "Austigen" de procedência da firma Hyland, Divisão dos Laboratórios Travenol, Califórnia, U.S.A.. Após eletroforese de $60 \mathrm{mi}$ nutos a $30 \mathrm{~mA}$, as placas de ágar foram lavadas em água destilada, durante 15 minutos, sendo as linhas de precipitação lidas com auxílio do "imuno-iluminador" Hyland.

\section{RESULTADOS}

Os soros dos 30 casos de sindrome de Down (cujas idades variaram entre 2 e 16 anos), bem como de 28 irmãos normais dessas crianças e de 19 de suas mães foram negativos para HBAg.

\section{DISCUSSAO}

Os casos de síndrome de Down estão intimamente ligados à história do HBAg. Logo após a descoberta de Blumberg e col. ${ }^{1}$ de um novo antígeno que apareceu no soro de um aborígene australiano, outros estudos sugeriram a relação desse antígeno com algumas formas de leucemia ${ }^{2,3}$. Como já se conhecia o fato de que pacientes com síndrome de Down (mongolóides) têm alta freqüência de leucemia, novas pesquisas passaram a relacionar o HBAg com a síndrome de Down ${ }^{18}$. Em seguida, a lepra lepromatosa ${ }^{11}$ e hepatite ${ }^{14}, 15$, inclusive hepatites associadas à sindrome de Down ${ }^{20}$ passaram a ser também relacionadas ao HBAg. Blumberg e col. ${ }^{7,10,14}$, verificando que esse antígeno era encontrado em grandes populações, presumivelmente normais, sugeriram que a suscetibilidade ao antígeno estaria ligada à hereditariedade. Esses dados não foram confirmados e, hoje, o HBAg está comprovadamente associado ao vírus da hepatite $B$. 
Krugman e Giles ${ }^{13}$ deram grande impulso ao estudo etiológico da hepatite viral, determinando a existência de dois virus, hoje conhecidos como vírus da hepatite $\mathrm{A}$ e vírus da hepatite $\mathrm{B}$. Seus trabalhos foram executados na Escola Estadual de Willowbrook, para retardados mentais, em Staten Island, New York e, pela primeira vez, foi reconhecida a natureza endêmica das hepatites. Mediante técnicas de imunodifusão e de fixação de complemento esses autores demonstraram que, de 621 pacientes internados entre 1965 e 1970, escolhidos ao acaso entre mais de 5.000 internados, 15 a $30 \%$ apresentavam reações positivas para HBAg.

Blumberg e col., na Colônia Estadual de Nova Lisboa (New Jersey) tinham anteriormente revelado a incidência de $25 \%$ de HBAg positivos em pessoas com síndrome de Down e apenas 5\% em pacientes com "epilepsias". Baseados nisso, esses autores tinham concluído que a alta incidência de HBAg na síndrome de Down não seria apenas devido à internação dos doentes mas também resultava de uma infecção de origem materna. Esses dados foram baseados em uma única amostra de sangue de cada paciente e não estavam relacionados com a epidemiologia da hepatite naquela colônia ou em outras instituições onde os pacientes pudessem ter estado previamente internados.

Os trabalhos de Krugman e Giles ${ }^{13}$ mostraram uma incidência geral de HBAg em 18,6\% de homens mongolóides e $15 \%$ de homens com outras deficiências mentais. Ambos os grupos estavam em Willowbrook há seis anos e tinham tido a mesma oportunidade de exposições à hepatite. Entre crianças com síndrome de Down obtiveram $43 \%$ de positividade para HBAg e apenas $24,4 \%$ de positividade em crianças com outras causas de retardamento mental. Os autores justificaram essa diferença pelo maior contato das crianças mongolóides em Willowbrook, pois eram atendidos em ambulatório antes de serem internados e os próprios internamentos eram mais precoces.

Além disso, Szmuness e col. verificaram que a probabilidade de doentes internados em instituições para retardados mentais se tornarem crônicas é maior se a primeira exposição à infecção se der precocemente na vida.

Hoje sabemos que o HBAg persiste no sangue de pacientes com síndrome de Down, especialmente em grandes instituições, onde é mais provável a propagação da infecção.

\section{RESUMO}

Os autores demonstraram a ausência de HBAg no soro de 30 pacientes com síndrome de Down tratados em ambulatório (idades de 2 a 16 anos), bem como em 28 irmãos e em 19 de suas mães. Após discutir o antigo conceito que relacionava a síndrome de Down com HBAg, os autores confirmam a observação de que em pacientes com síndrome de Down, não hospitalizados, a incidência de HBAg é semelhante à da população geral. 


\section{SUMMARY}

\section{Hepatitis $B$ antigen in Down's syndrome}

The authors have shown the absence of HBAg in the blood of $30 \mathrm{pa}$ tients with Down's syndrome treated in ambulatory conditions (age from 2 to 16 years), as well as in 28 brothers or sisters and in 19 of their mothers. After discussing the old concept of relationship between Down's syndrome and HBAg, the authors confirmed the observation that in non-institucionalized patients with the Down's syndrome, the incidence of HBAg is similar to the whole population.

\section{REFERENCIAS}

1. BLUMBERG, B. S. - Polymorphisms of the serum proteins and the development of isoprecipitins in transfused patients. Bull. N.Y. Acad. Med. 40:377, 1964.

2. BLUMBERG, B. S. - An inherited serum isoantigen in leukemia and Down's syndrome. J. Clin. Invest. 45:988, 1966.

3. BLUMBERG, B. S. - Australia antigen, hepatitis and leukemia. Tokyo J. Med. Sci. $76: 342,1968$.

4. BLUMBERG, B. S. - In Pollard, M. (ed.) Perspectives in virology, vol. 7: From molecules to man, pag. 295. Academic Press, New York, 1971.

5. BLUMBERG, B. S.; ALTER, H. J. \& VISNICH, S. - A "new" antigen in leukemia sera. J. Am. Med. Ass. 191:541, 1965.

6. BLUMBERG, B. S.; DRAY, S. \& ROBINSON, J. C. - Antigen polymorphism of a low-density beta lipoprotein allotypy in human serum. Nature 194:656, 1962.

7. BLUMBERG, B. S.; FRIEDLAENDER, J. S. \& WOODSIDE, A. - Hepatitis and Australia antigen. Autossomal recessive inheritance of suscetibility to infection in humans. Proc. Soc. Nat. Acad. Sci. 62:1108, 1969.

8. BLUMBERG, B. S.; GERSTLEY, J. B. S. \& HUNGERFORD, D. A. - A serum antigen (Australia antigen) in Down's syndrome, leukemia and hepatitis. Ann. Int. Med. 66:924, 1967.

9. BLUMBERG, B. S.; GERSTLEY, B. J. S. \& LONDON, W. T. - Hepatitis virus and Australia antigen. J. Clin. Invest. 48:9, 1969.

10. BLUMBERG, B. S.; MELARTIN, L. \& GUINTO, R. A. - Family studies of a "new" human serum isoantigen system (Australia antigen). Am. J. Hum. Genit. 18:594, 1966.

11. BLUMBERG, B. S.; MELARTIN, L. \& LECHAT, M. - Association between lepromatous leprosy and Australia antigen. Lancet 2:173, 1967.

12. BLUMBERG, B. S.; SUTNICK, A. I. \& LONDON, W. F. - Hepatitis and leukemia; their relation to Australia antigen. Bull. N.Y. Acad. Med. 44:1566, 1968.

13. KRUGMAN, S. \& GILES, J. P. - Viral hepatitis: new light on an old disease. J. Am. Med. Ass. 212:1019, 1970.

14. LONDON, W. T.; SUTNICK, A. I. \& BLUMBERG, B. S. - Australia antigen and acute viral hepatitis. Ann. Int. Med. 70:55, 1969

15. LONDON, W. T.; SUTNICK, A. I. \& BLUMBERG, B. S. - Australia antigen and hepatitis. J. Am. Med. Ass. 207:1895, 1969.

Endereço: Prof. Roberto de Almeida Moura - Av. Angélica 1832 - 01227 São Paulo SP - Brasil. 